\title{
Review of the safety, efficacy and patient acceptability of the combined dienogest/ estradiol valerate contraceptive pill
}

REVIEW

This article was published in the following Dove Press journal:

International Journal of Women's Health

20 August 2010

Number of times this article has been viewed

\section{Maurizio Guida \\ Giuseppe Bifulco \\ Attilio Di Spiezio Sardo \\ Mariamaddalena Scala \\ Loredana Maria Sosa \\ Fernandez \\ Carmine Nappi}

Dipartimento di Scienze Ostetriche Ginecologiche Urologiche e Medicina della Riproduzione Umana, Università degli Studi “Federico II”, Napoli, Italia

Correspondence: Attilio Di Spiezio Sardo Via Vecchia San Gennaro 30, CAP 80078, Pozzuoli, Napoli, Italia

Tel +3397720932

Email cdispie@tin.it

\begin{abstract}
The aim of this review is to define the role of the combined dienogest (DNG)/estradiol valerate $(\mathrm{E} 2 \mathrm{~V})$ contraceptive pill, in terms of biochemistry, metabolic and pharmacological effects and clinical application as well. E2V is the esterified form of $17 \beta$-estradiol (E2), while dienogest is a fourth-generation progestin with a partial antiandrogenic effect. The cycle stability is achieved with 2 to $3 \mathrm{mg}$ DNG, supporting contraceptive efficacy. In this new oral contraceptive, E2V is combined with DNG in a four-phasic dose regimen (the first two tablets contain $3 \mathrm{mg}$ E2V; the next five tablets include $2 \mathrm{mg}$ E2V $+2 \mathrm{mg}$ DNG, followed by 17 tablets with $2 \mathrm{mg}$ E2V $+3 \mathrm{mg}$ DNG; followed by two tablets with $1 \mathrm{mg}$ E2V only, and finally two placebo tablets). Duration and intensity of scheduled withdrawal bleeding are lower with this contraceptive pill, whereas the incidence and the intensity of intra-cyclic bleeding are similar to the other oral contraceptive. With this new pill the levels of high density lipoprotein increased, while the levels of prothrombin fragment $1+2$ and D-dimer remained relatively unchanged; the levels of sex hormone binding globulin, cortisol binding globulin, thyroxine binding globulin increased. The most frequently reported adverse events are: breast pain, headache, acne, alopecia, migraine, increase of bodyweight. The satisfaction rate is about $79.4 \%$.
\end{abstract}

Keywords: estradiol valerate, dienogest, combined oral contraceptive, four-phasic regimen, contraceptive safety

\section{Introduction}

Oral contraceptives were first approved for contraceptive use in the United States in 1960, and are a very popular form of birth control as well as a widely accepted method of contraception. They are currently used by more than 100 million women worldwide and by almost 12 million women in the United States. ${ }^{1}$

Despite their undoubted popularity, some women experience adverse events while taking oral contraceptives, including breast tenderness, headache, nausea and loss of libido. In addition, epidemiological studies have suggested an association between oral contraceptive use and an increased risk of arterial and venous thrombotic events. ${ }^{2}$

In recent years, thanks to the availability of the new synthetic progestins as well as natural estrogens, new oral contaceptives showed high patient tolerance.

In May 2009, a new oral contraceptive became available in several European countries and in July 2009 Bayer submitted Qlaira ${ }^{\circledR}$ to the US Food and Drug Administration (FDA). Approval has been requested for two indications: oral contraception and treatment of menorrhagia and/or hypermenorrhea without organic pathology, in women desiring oral contraception. 
In this oral contraceptive, estradiol valerate $(\mathrm{E} 2 \mathrm{~V})$ is combined with the progestin dienogest (DNG) in a four-phasic dose regimen, incorporating an estrogen step-down and a progestin step-up over 26 days, with two more placebo tablets, making up a treatment of up to 28 days (Figure 1) The first two tablets contain $3 \mathrm{mg}$ E2V to prime the endometrium. The next five tablets include $2 \mathrm{mg}$ E2V and $2 \mathrm{mg}$ DNG followed by 17 tablets with $2 \mathrm{mg}$ E2V and $3 \mathrm{mg}$ DNG. Finally, there are two tablets with $1 \mathrm{mg}$ E2V only and two placebo tablets. $^{3}$

A continuous intake for 28 days has a double purpose:

1. Optimization of the pharmacological profile, maintaining stable plasma hormone levels, and consequently reducing or eliminating catamenial symptoms (premenstrual symptoms, headache, dysmenorrhea), associated with decreasing estrogen levels, thus improving general wellbeing. 5

2. Improving adherence: the daily intake, without pauses, helps women to maintain a more regular intake, avoiding the frequent omission that may otherwise reduce contraceptive efficacy and increase adverse effects, such as intermenstrual spotting. ${ }^{5}$

The early estrogenic dominance guarantees the endometrial proliferation and sensitizes the tissue to the action of progestin, while progestogenic dominance in the middle and at the end of the cycle, followed by a moderate estrogenic activity in the final stage, ensure satisfactory endometrial stability. The brief 2-day interval without hormones has proved to be enough to ensure regular bleeding in most of the women under Qlaira ${ }^{\circledR}$ treatment, compared with the conventional association of ethinylestradiol (EE). ${ }^{6}$

The aim of this review was to define the role of the combined DNG/E2V contraceptive pill (Qlaira ${ }^{\circledR}$; Bayer
Schering Pharma AG, Berlin, Germany) in terms of biochemistry, metabolic and pharmacological effects, and clinical application, referring to recently published oral contraceptives trial data, performed on women aged $>18$ and $<50$ years.

\section{Pharmacokinetic profile E2V}

E2V (Figure 2) is the esterified form of $17 \beta$-estradiol (E2); it is rapidly and completely absorbed and hydrolyzed to natural estradiol (E2) during the first gastrointestinal tractpassage; ${ }^{6}$ $\mathrm{E} 2 \mathrm{~V}$ is almost identical to E2 in terms of pharmacokinetics, and exactly identical in pharmacodynamics and clinically; $\mathrm{E} 2 \mathrm{~V}$ releases $\mathrm{E} 2$, which is identical to the endogenously produced $\mathrm{E} 2 ; 1 \mathrm{mg}$ of $\mathrm{E} 2 \mathrm{~V}$ is equivalent to $0.76 \mathrm{mg}$ of $\mathrm{E} 2$, based on molecular weight. ${ }^{7}$

\section{Absorption}

E2V is completely absorbed by the intestinal mucosa and cleavage to estradiol and valeric acid during first liver-passage. ${ }^{3}$

\section{Distribution}

Thirty-eight percent of E2 is bound to sex hormone binding globulin (SHBG), $60 \%$ to albumin, and $2 \%$ to $3 \%$ circulates in a free form (induction of SHBG to $150 \%$ during a 28 daily cycle). ${ }^{4}$

The serum E2 concentration remains stable during the 28-day treatment period; ${ }^{8}$ the apparent volume of distribution is $\sim 1.2 \mathrm{~L} / \mathrm{kg}^{3}$

\section{Metabolism}

Ninety-five percent is metabolized before entering the systemic circulation. Main metabolites are estrone, estrone sulfate and estrone glucuronide. ${ }^{4}$

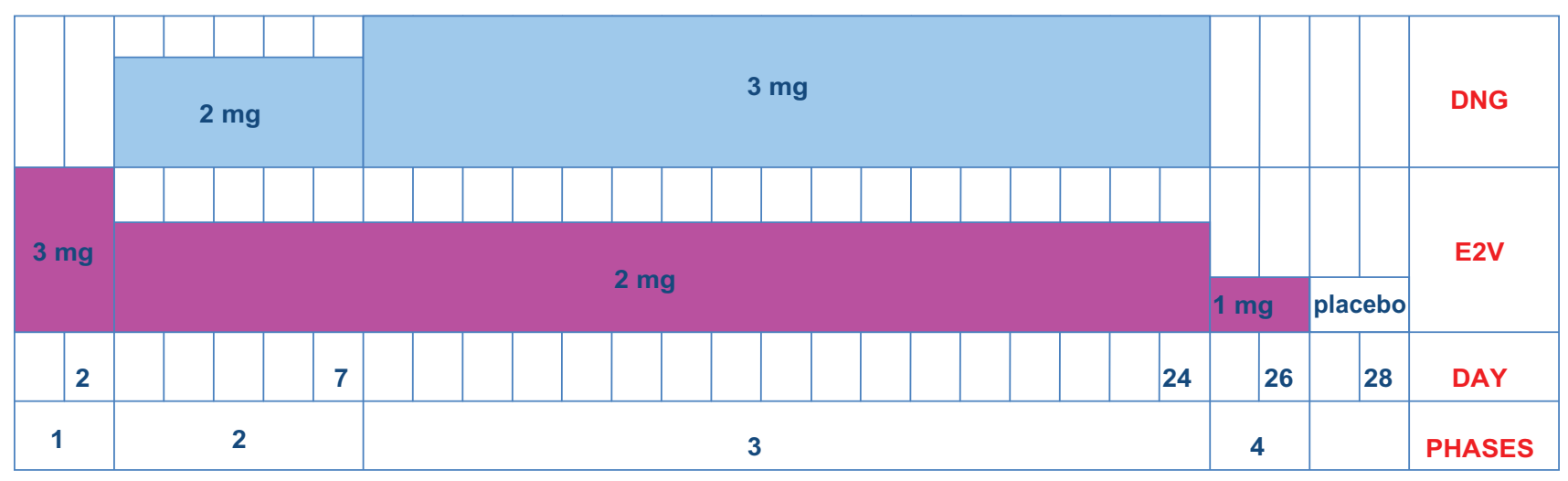

Figure I Dose regimen for Qlaira ${ }^{\circledR}$ (one cycle).

Abbreviations: DNG, dienogest; E2V, estradiol valerate. 


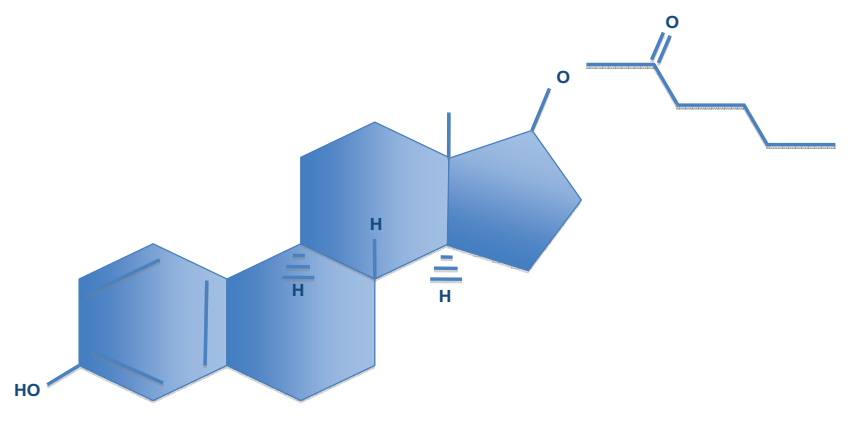

Figure 2 Molecular structure of estradiol valerate.

\section{Elimination}

Terminal half-life is 13 to 20 hours due to enterohepatic recirculation and a large circulating pool of estrogen sulfates and glucuronides (90-min plasma half-life of circulating estradiol). ${ }^{4}$

Estradiol and its metabolites are predominately excreted in the urine. Minimal $(\sim 10 \%)$ excretion occurs via the feces. ${ }^{3}$

\section{DNG}

DNG (Figure 3) has particular properties: it is similar to 19-nortestosterone derivatives (Figure 4) with a short plasma half-life (11 hours), and has a strong progestational effect on the endometrium, high oral bioavailability (more that $90 \%$ ); it is similar to progesterone derivatives with a relatively low inhibition of gonadotropin secretion, doses in milligram range, and anti-androgenic activity ( $40 \%$ of cyproterone acetate). ${ }^{9}$

Some specific properties of DNG are the absence of interaction with specific transport proteins (SHBG, cortisol binding globulin $[\mathrm{CBG}]$ ), and a high concentration of the unbound substance in serum: $10 \%$ unbound, $90 \%$ bound to albumin. ${ }^{10,11}$

\section{Absorption}

DNG is rapidly and almost completely absorbed with a bioavailability of $\sim 90 \%{ }^{4}$

\section{Distribution}

Ten percent of DNG is unbound, $90 \%$ is bound to albumin, with no binding to SHBG and CBG. ${ }^{3}$

\section{Metabolism}

DNG is completely metabolized by cytochrome P450 3A4 (CYP3A4), hydroxylation and conjugation, mostly inactive metabolites. Unchanged DNG dominance is due to very quick excretion of metabolites. ${ }^{4}$

\section{Elimination}

DNG plasma half-life is approximately 11 hours. Only $1 \%$ of the unchanged drug is excreted; urinary to fecal excretion

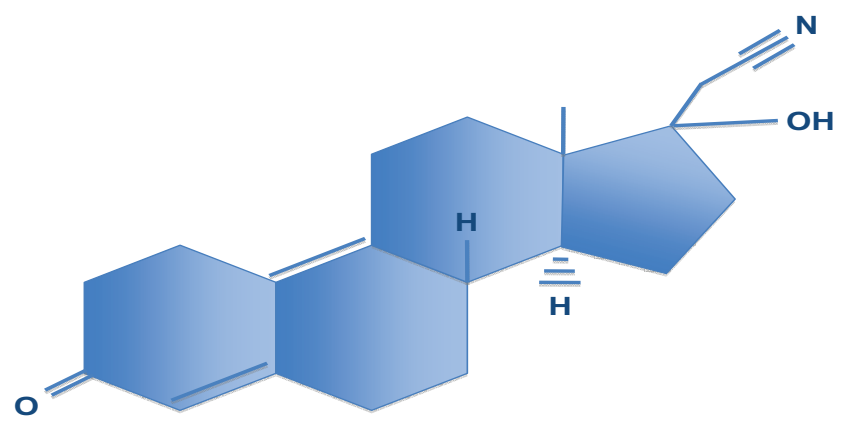

Figure 3 Molecular structure of dienogest.

ratio is $3: 1$, with $42 \%$ and $63 \%$ of an oral dose excreted renally within the first 24 hours and during the first 6 days. ${ }^{3}$ Approximately, $86 \%$ of a DNG dose is excreted via the urine or feces in 6 days. ${ }^{3}$ The pharmacologically inactive metabolites of DNG are rapidly excreted. ${ }^{3}$

Concomitant administration of DNG and CYP3A4 inducers may result in elevated DNG clearance rates. ${ }^{3}$ Concurrent treatments with CYP3A4 inhibitors may elevate plasma DNG concentration. ${ }^{3}$

The steady state is reached after 3 days which is not influenced by SHBG levels. There is no relevant accumulation. ${ }^{4}$

\section{Pharmacodynamic profile}

E2 is considered weaker than EE in terms of hepatic protein synthesis induction, as demonstrated in clinical studies assessing SHBG, angiotensinogen and hemostatic parameters. ${ }^{12-15}$

The DNG has a protective effect on the endometrium and the cycle stability is achieved with 2 to $3 \mathrm{mg}$ DNG; the anti-estrogenic effect on the cervical mucus supports the contraceptive efficacy; no relevant anti-estrogenic effect on vaginal epithelium is reported, while there is an anti-proliferative effect on endometriosis tissue. ${ }^{4}$

No clinically relevant effects have been observed with up to $20 \mathrm{mg}$ /day DNG over 24 weeks on lipid metabolism, liver enzymes, hemostatic parameters and thyroid gland metabolism. In particular, DNG does not attenuate the estrogen-induced alterations in the hepatic production of hormone-sensitive proteins, including hemostatic factors, because of its anti-androgenic activity. ${ }^{16-19}$

In a prospective randomized study, ${ }^{20}$ the effect of E2-only therapy was compared to a combined E2/progestin treatment, regarding the excretion of vasoactive mediators, surrogating a possible effect on the vascular system. The progestin used was DNG, while the estrogen was E2 $\mathrm{V}^{20}$

Twenty-five women received E2V ( $2 \mathrm{mg} /$ day) for 3 months and 27 women were treated with E2V ( $2 \mathrm{mg} /$ day) combined with DNG ( $2 \mathrm{mg} /$ day $)$ in a continuing regimen. ${ }^{20}$ 


\section{PROGESTOGENS}

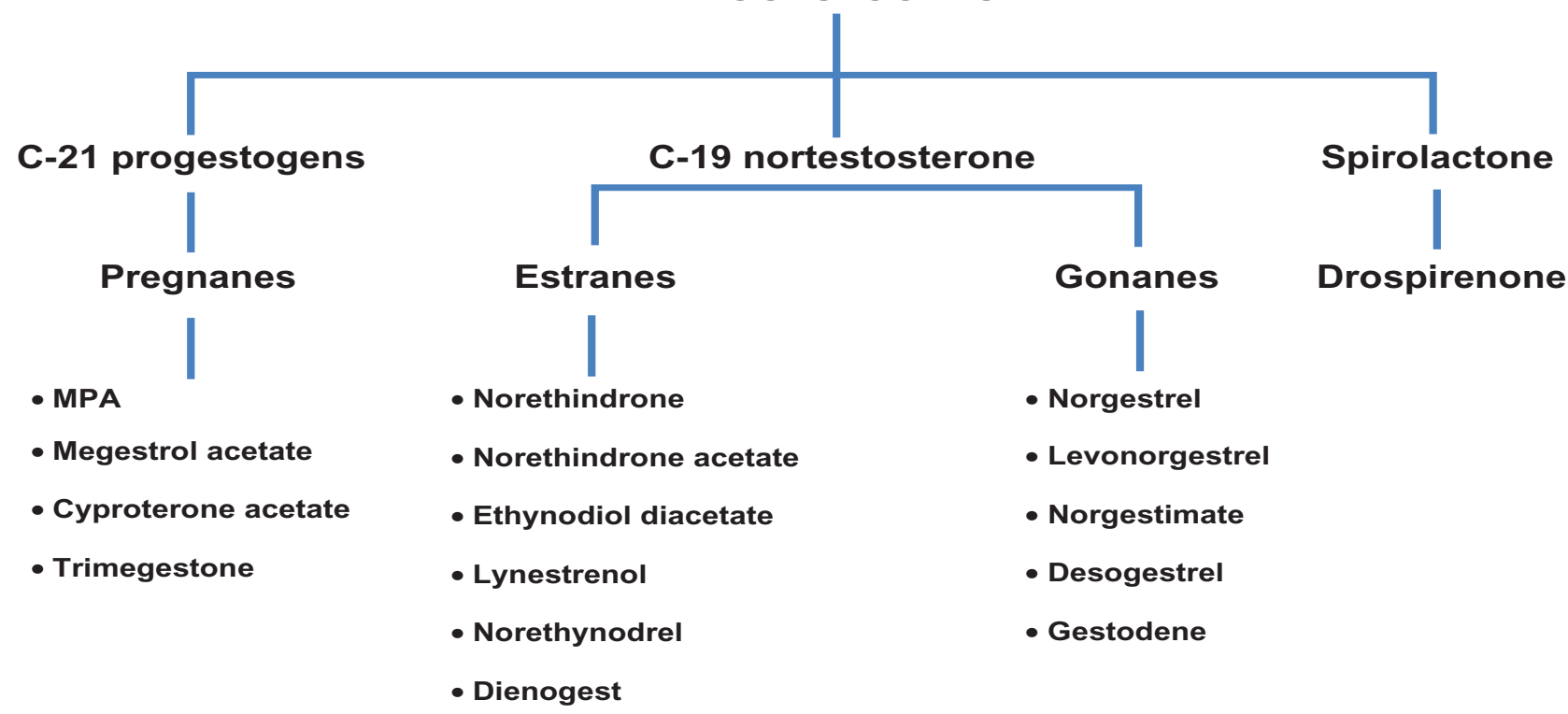

Figure 4 Classification of progestogens.

E2V alone significantly increases the excretion of cyclic guanosine monophosphate (cGMP) and serotonin, suggesting vasodilating effects. Furthermore, the prostacyclin/ thromboxane ratio, known to be crucial for the relationship between vasorelaxation and vasoconstriction, increased as well. No significant changes were found for urodilatin, which is known to elicit different effects on the cardiovascular and renal systems, respectively. ${ }^{20}$

Combined E2V/DNG therapy also led to significant increases in cGMP and serotonin excretion, suggesting that progestin addition for 3 months does not affect these markers. However, in contrast to estrogen-only treatment, there was no significant increase in the prostacyclin/thromboxane ratio, which can be explained by the antagonistic action of the progestin. The excretion of urodilatin significantly increased, probably due to the counterbalancing progestin effects on the renal vascular system..$^{20}$ In conclusion, the changes in vasoactive markers suggest a potential estrogenic vasorelaxant effect. Since there were no significant differences between the two groups, possible vascular effects of DNG, evaluated for the first time, might not be of clinical relevance, at least not on women without cardiovascular diseases. ${ }^{20}$

\section{Interactions}

Two studies ${ }^{21}$ investigated the effects of CYP3A4 induction (study 1; E2V/DNG on days 1 to 17, rifampicin $600 \mathrm{mg}$ on days 12 to $16[\mathrm{n}=16]$ ) and inhibition (study 2; E2V/DNG on days 1 to 14 , ketoconazole $400 \mathrm{mg}$ or erythromycin
$500 \mathrm{mg} 3$ times daily on days 8 to $14[\mathrm{n}=24]$ ) on the pharmacokinetic profiles of E2 and DNG in healthy post-menopausal women. With rifampicin, the geometric mean ratios (day 17 vs 11) of E2 AUC (0 to 24 hours) and $\mathrm{C}_{\max }$ were $56 \%(90 \%$ CI $53.1 \%$ to $59.8 \%)$ and $75 \%$ (66.9\%-84.4\%), respectively. The corresponding ratios for DNG were $17 \%$ (15.6\% to $18.7 \%$ ) and $48 \%$ (44.8\% to $51.6 \%)$, respectively. With ketoconazole, the geometric mean ratios (day 14 vs 7) of $\mathrm{E} 2 \mathrm{AUC}$ (0 to 24 hours) and $\mathrm{C}_{\max }$ were $157 \%$ (145\% to $171 \%$ ) and $165 \%$ (149\% to $182 \%)$, respectively. The corresponding ratios for DNG were $286 \%$ (263\% to $311 \%$ ) and $194 \%$ (184\% to $205 \%)$, respectively. With erythromycin, the ratios for E2 were $133 \%$ (118\% to $150 \%)$ and $151 \%$ (136\% to $168 \%$ ), respectively, and the ratios for DNG were $162 \%(146 \%$ to $180 \%)$ and $133 \%(123 \%$ to $144 \%)$, respectively. Therefore, there is a significant interaction between inducers and inhibitors of CYP3A4 activity and E2V/DNG. ${ }^{21}$

\section{Efficacy}

\section{Inhibition of ovulation}

Natural E2 has proved to be unsatisfactory in respect to cycle control. To investigate this aspect, two randomized, open label, Phase II studies were carried out with the purpose of identifying the optimal dose of E2 V and DNG, as well as the duration of their intake during a 28-day cycle.

The first study compared two regimens (regimens 1A and $2 \mathrm{~A})^{22}$ with similar dosages of DNG, but with a different duration of administration. Having established in the first 
study that the duration of application of regimen $2 \mathrm{~A}$ was most suitable, but that the dosages of DNG were too low for effective ovulation inhibition, a second study, comparing two regimens (regimens 2B and 2C) with similar duration of treatment, but with increased dosages of DNG, was undertaken. ${ }^{22}$

Indeed, as DNG does not contain any ethinyl group, the absence of this inhibitory mechanism could explain the relatively short half-life and the higher dose necessary for ovulation inhibition of DNG compared to, for example, levonorgestrel (LNG). ${ }^{23}$

Both studies were carried out to evaluate ovulation inhibition, which was assessed by transvaginal ultrasound monitoring of follicle size and analysis of serum E2 and progesterone levels, and classified according to the 6-point scoring system of Hoogland and Skouby. ${ }^{24}$

The primary efficacy end point in both studies was the proportion of women with a Hoogland score of 5 (luteinized unruptured follicle) or a Hoogland score of 6 (ovulation) at cycle $2 .{ }^{22}$ A Hoogland score of 6 is defined as a ruptured follicle-like structure (FLS) of $13 \mathrm{~mm}$ with serum progesterone of $5 \mathrm{nmol} / \mathrm{L}$ and E2 of $0.1 \mathrm{nmol} / \mathrm{L}$. A Hoogland score of 5 was considered as critical as a Hoogland score of 6 , since a persisting FLS may still develop into a ruptured FLS in subsequent cycles. ${ }^{22}$

In studies 1 and 2, 192 and 203 women were analyzed, respectively. In study 1,10 women $(10.9 \%)$ in regimen $1 \mathrm{~A}$ and six women (6.4\%) in regimen $2 \mathrm{~A}$ had a Hoogland score of 5 or 6 . In study 2 , three women $(3.1 \%)$ in regimen $2 \mathrm{~B}$ and one woman $(1.0 \%)$ in regimen $2 \mathrm{C}$ had a Hoogland score of 5 or 6 . There were no safety concerns with any of the regimens. ${ }^{22}$

The results of these studies identified a four-phasic oral contraceptive preparation comprising E2V/DNG that provides efficient ovulation inhibition. ${ }^{22}$

The studies were performed in a stepwise manner in order to determine, firstly, a suitable duration of treatment (study 1) and, secondly, a suitable dose of DNG (study 2) for effective ovulation inhibition. ${ }^{22}$ Each step increased the ovulationinhibition potency remarkably, with the result that regimen $2 \mathrm{~B}$ (with E2V $3 \mathrm{mg}$ in days 1 to 2, E2V $3 \mathrm{mg} / \mathrm{DNG} 2 \mathrm{mg}$ in days 3 to $7, \mathrm{E} 2 \mathrm{~V} 2 \mathrm{mg} / \mathrm{DNG} 3 \mathrm{mg}$ in days 8 to 24 and $\mathrm{E} 2 \mathrm{~V} 1 \mathrm{mg}$ in days 27 to 28) proved to be capable of guaranteeing the best contraceptive efficacy and safety in Phase III studies. ${ }^{22}$ This formulation contained the lowest dose of DNG that inhibited more than $95 \%$ of ovulations in cycle $2 .^{22}$

A large multicenter study recruited 1377 women for 20 cycles of follow-up. The corrected Pearl Index (PI) for all those entering the study was 0.34 , with Qlaira ${ }^{\circledR}$ being equally effective in those over 35 and under $35 .{ }^{25} \mathrm{~A}$ further study comparing Qlaira ${ }^{\circledR}$ with a 21/7 $20 \mu \mathrm{g}$ EE/100 $\mu \mathrm{g}$ LNG pill (Miranova ${ }^{\circledR}$ ) resulted in just one method failure (in the Miranova $^{\circledR}$ group). ${ }^{7}$

Nevertheless, Qlaira ${ }^{\circledR}$ has a similar PI to conventional pills and its bleeding pattern in general is similar to that with a $20 \mu \mathrm{g} \mathrm{EE} / 100 \mu \mathrm{g} \mathrm{LNG} \mathrm{pill.}{ }^{25}$

\section{Bleeding parameters and cycle control}

The early estrogen dominance guarantees the initial endometrial proliferation and sensitizes the tissue to the action of progestogens. The Qlaira ${ }^{\circledR}$ regimen with the dominance of DNG in the middle and the later part of the cycle, followed by a moderate estrogenic activity during the final part of the cycle, ensures an acceptable endometrial stability. ${ }^{6}$ Instead, the use of E2 as a part of a monophasic or a biphasic regimen has a poor cycle control. ${ }^{26-28}$ In a randomized, double-blind study, E2V/DNG and EE/LNG demonstrated an acceptable bleeding pattern and cycle control, according to several co-primary endpoints, in 798 women aged 18 to 50 years (399 in each treatment group), who received seven cycles of E2V/DNG or EE/LNG. ${ }^{7}$ The primary efficacy endpoints were the number of days and episodes of bleeding/spotting for a 90-day period, the length of the bleeding/spotting episodes and the incidence and characteristics of scheduled (withdrawal) and unscheduled (intracyclic) bleeding for cycle. ${ }^{7}$

In particular, withdrawal bleeding was experienced by significantly ( $P<0.0001$ for each cycle) fewer E2V/DNG recipients $(77.7 \%$ to $83.2 \%)$ than $\mathrm{EE} / \mathrm{LNG}$ recipients $(89.5 \%$ to $93.8 \%)$ over seven cycles, with a mean absence of withdrawal bleeding in $19.4 \%$ (range $16.8 \%$ to $22.3 \%$ ) vs $7.7 \%$ (range $6.2 \%$ to $10.5 \%$ ) of women. ${ }^{7}$ The absence of withdrawal bleeding was experienced at least once over the seven cycles by $56.9 \%$ and $37.8 \%$ of women receiving E2V/DNG and EE/LNG, with $21.2 \%$ and $22.2 \%$ experiencing the absence of withdrawal bleeding once and $12.2 \%$ and $7.1 \%$ experiencing the absence of withdrawal bleeding twice. ${ }^{7}$ An absence of all withdrawal and intracyclic bleeding occurred in $15.4 \%$ and $4.5 \%$ of cycles with E2V/DNG and EE/LNG. ${ }^{7}$ The mean length of withdrawal bleeding was significantly $(P<0.05)$ shorter in E2V/DNG recipients (4.1 to 4.7 days) than $\mathrm{EE} / \mathrm{LNG}$ recipients (5.0 to 5.2 days). ${ }^{7}$ In a descriptive analysis, $56.3 \%$ to $62.5 \%$ and $37.5 \%$ to $43.8 \%$ of women in the respective treatment groups experienced 'spotting' and/or 'light bleeding' (data derived from a graph). ${ }^{7}$ A significant difference ( $P$-value not reported) in the maximum intensity of withdrawal bleeding was observed between E2V/DNG and EE/LNG therapy; mean maximum intensity withdrawal 
bleeding scores were 3.2 to 3.3 per cycle with $\mathrm{E} 2 \mathrm{~V} / \mathrm{DNG}$ and 3.6 per cycle with EE/LNG. ${ }^{7}$ From the end of the exposure to the progestogen component, the median onset of withdrawal bleeding was days 2 to 3 with E2V/DNG and day 3 with EE/LNG. ${ }^{9}$

For instance, no significant difference in the incidence of intracyclic bleeding over seven cycles was observed between the E2V/DNG (10.5\% to $18.6 \%$ of women) and EE/LNG (9.9\% to $17.1 \%)$ groups in the double-blind study, with a heavier intensity observed less often with E2V/DNG than with EE/LNG (mean $2.4 \%$ vs $4.0 \%$ of women). ${ }^{7}$

Average hemoglobin levels remained unchanged throughout the treatment in both groups. ${ }^{7}$ There was one unintended pregnancy attributed to method failure, during the treatment in a woman who received EE/LNG. ${ }^{7}$

In another non-comparative, multicenter study, in which 1391 women were enrolled (1377 comprised the full analysis set and 1074 completed treatment), E2V/DNG demonstrated a high contraceptive efficacy. ${ }^{29}$ Six of the pregnancies were attributed to method failure, resulting in an adjusted PI, based on 1786.5 women-years of exposure, of 0.34 (upper limit of $95 \%$ CI 0.73$).{ }^{29}$ In a subset of women aged 18 to 35 participating in this study, 12 pregnancies occurred, five of which were attributed to method failure; the unadjusted PI, based on 1277.5 women-years of exposure, was 0.94 (upper limit of $95 \%$ CI 1.65), while the adjusted PI, based on 1268.5 women-years of exposure, was 0.40 (upper limit of $95 \%$ CI 0.92). ${ }^{29}$ The Kaplan-Meier estimate of the cumulative pregnancy rate for this subset of women was 0.0142 (95\% CI 0.0080 to 0.0251$).{ }^{29}$

Moreover withdrawal bleeding was generally stable throughout this study, with $76.8 \%$ to $81.6 \%$ of women experiencing withdrawal bleeding during cycles 1 to 19 of E2V/DNG therapy, although the intensity and duration of withdrawal bleeding progressively decreased with treatment (no data or statistical analysis reported). ${ }^{29}$

A minority of women experienced intracyclic bleeding in the double-blind ${ }^{7}$ and non-comparative ${ }^{29}$ studies.

\section{Metabolism}

Various hormone parameters and serum-binding globulins were investigated in a double-blind, controlled, randomized, four-arm, bicentric clinical study. ${ }^{30}$ Four groups with 25 volunteers each, were treated for six cycles with monophasic combination containing 21 tablets with either $30 \mu \mathrm{g} \mathrm{EE}+2 \mathrm{mg} \mathrm{DNG}, 20 \mu \mathrm{g} \mathrm{EE}+2 \mathrm{mg} \mathrm{DNG}, 10 \mu \mathrm{g}$ $\mathrm{EE}+2 \mathrm{mg} \mathrm{E} 2 \mathrm{~V}+2 \mathrm{mg} \mathrm{DNG}$, or $20 \mu \mathrm{g} \mathrm{EE}+100 \mu \mathrm{g}$ LNG. The DNG-containing oral contraceptives caused a higher increase in SHBG and thyroxine binding globulin (TBG) levels than the LNG-containing preparation. There was a reduction of dehydroepiandrosterone sulfate throughout the study in all treatment groups, which appeared to be enhanced with the increasing length of treatment. ${ }^{30}$

There was a rise in $\mathrm{CBG}$ in all groups, which was most pronounced in women treated with $30 \mathrm{EE} / \mathrm{DNG}(+90 \%)$ and least with $\mathrm{EE} / \mathrm{E} 2 \mathrm{~V} / \mathrm{DNG}(+55 \%)$, indicating a minor hepatic impact of $2 \mathrm{mg}$ E2V compared to 20 or $30 \mu \mathrm{g} \mathrm{EE}$, and no effect of the progestogen component. It is known that the treatment with low-dose oral contraceptives generally does not influence prolactin levels, ${ }^{31-35}$ except from a sporadic and transitory hyperprolactinemia in predisposed women. ${ }^{36,37}$

In contrast to $\mathrm{EE}$, the use of $\mathrm{E} 2 \mathrm{~V}$ in oral contraceptives seemed to cause a time-dependent significant rise in prolactin levels that was $40 \%$ higher after six treatment cycles, while the cycle control was better with the oral contraceptives containing $30 \mu \mathrm{g} \mathrm{EE}^{30}$ (Table 1).

Another single center, open-label, randomized controlled trial was performed to compare the metabolic effects of a new four-phasic oral contraceptive comprising E2V and DNG with $\mathrm{EE}$ and LNG. Women aged 18 to 50 years received, for seven cycles, a four-phasic regimen containing DNG (2 days E2V $3 \mathrm{mg}, 5$ days E2V $2 \mathrm{mg} / \mathrm{DNG} 2 \mathrm{mg}, 17$ days E2V $2 \mathrm{mg} / \mathrm{DNG}$ $3 \mathrm{mg}$, 2 days E2V $1 \mathrm{mg}, 2$ days placebo; $\mathrm{n}=30$ ) or a sequential regimen of EE and LNG (6 days EE $0.03 \mathrm{mg} / \mathrm{LNG} 0.05 \mathrm{mg}$, 5 days EE $0.04 \mathrm{mg} / \mathrm{LNG} 0.075 \mathrm{mg}, 10$ days EE $0.03 \mathrm{mg} / \mathrm{LNG}$ $0.125 \mathrm{mg}, 7$ days placebo; $\mathrm{n}=28) .{ }^{38}$ The main efficacy variable was the individual-specific relative variation in high-density lipoprotein and low-density lipoprotein cholesterol from baseline to cycle $7 .{ }^{38}$ Hemostatic parameters, carbohydrate metabolism and hormone levels were also investigated. ${ }^{38}$ The change in high-density lipoprotein cholesterol was $+7.9 \% \pm$ $21.8 \%$ for women using E2V and DNG and $-2.3 \% \pm 14.4 \%$ for $\mathrm{EE}$ and $\mathrm{LNG}(P=0.055)$. The corresponding changes for low-density lipoprotein cholesterol were $-6.5 \% \pm 15.9 \%$ and $-3.0 \% \pm 17.4 \%$, respectively $(P=0.458) .{ }^{38}$ In general, variations in hemostatic features were less pronounced with E2V and DNG than with EE and LNG. ${ }^{38}$ The carbohydrate metabolism pattern remained unchanged and within the normal limits in both groups. SHBG levels increased by $+62.7 \% \pm 50.5 \%$ and $+111.6 \% \pm 48.0 \%$ for women using $\mathrm{E} 2 \mathrm{~V}$ and DNG, compared to EE and $\mathrm{LNG}$, respectively. ${ }^{38}$ Oral contraceptive containing E2V and DNG demonstrated a more favorable effect on lipid profiles and had a slight impact on hemostatic parameters compared with EE and LNG. No clinically important changes in metabolic features were observed in both treatment groups ${ }^{38}$ (Table 2). 
Table I Metabolic changes from E2V/DNG compared to EE/DNG and EE/LNG

\begin{tabular}{|c|c|c|c|c|}
\hline & \multicolumn{4}{|l|}{ Oral contraceptives } \\
\hline & $30 \mu \mathrm{g} E E / 2$ mg DNG & $20 \mu g$ EE/2 mg DNG & $10 \mu \mathrm{g} \mathrm{EE} / 2 \mathrm{mg}$ E2V/2 mg DNG & $20 \mu \mathrm{g} E E / / 00 \mathrm{mg}$ LNG \\
\hline SHBG & ++ & ++ & ++ & + \\
\hline TBG & ++ & ++ & ++ & + \\
\hline DHEAS & -- & -- & -- & -- \\
\hline CBG & +++ & ++ & + & ++ \\
\hline PRL & stable & stable & $\begin{array}{l}++ \\
\text { time dependent }\end{array}$ & stable \\
\hline
\end{tabular}

Abbreviations: EE, ethinylestradiol; DNG, dienogest; E2V, estradiol valerate; LNG, levonorgestrel; SHBG, sex hormone binding globulin; DHEAS, dehydroepiandrosterone sulfate; $C B G$, cortisol binding globulin; PRL, prolactin.

\section{Coagulation disorders}

One of the most relevant complications of oral contraceptive use is thromboembolic disease, and the relative risk of deep vein thrombosis (DVT) rises especially during the first year of use, suggesting an important role of predisposition and risk factors. ${ }^{39-42}$

Nevertheless, DVT is a rare event in young women, and consequently fairly reliable epidemiological findings cannot be expected before new formulations have been used by a large number of women for a sufficient period of time. As a surrogate, regulatory authorities require controlled studies on the effect of new oral contraceptive formulations or regimens on hemostatic parameters, even though no causal relationship has so far been established between oral contraceptive-induced changes in distinct hemostatic parameters and the risk of venous thromboembolic events (VTEs). ${ }^{43}$

The decrease in the incidence of VTEs after introduction of low-dose oral contraceptives containing $\leq 35 \mu \mathrm{g}$ EE suggested a causal association with the estrogen dose. ${ }^{39,44-46}$ This might be possible because changes in coagulation and fibrinolysis cascade were significantly lower with

Table 2 Metabolic change from E2V/DNG compared to EE/LNG

\begin{tabular}{llll}
\hline & \multicolumn{2}{l}{ Oral contraceptives } \\
\cline { 2 - 4 } & E2V/DNG & EE/LNG & P value \\
\hline HDL & $+7.9 \pm 21.8 \%$ & $-2.3 \pm 14.4 \%$ & 0.055 \\
LDL & $-6.5 \pm 15.9 \%$ & $-3.0 \pm 17.4 \%$ & 0.458 \\
SHBG & $62.7 \pm 50.5 \%$ & $111.6 \pm 48 \%$ & - \\
Prothrombin & stable & stable & \\
fragment I + 2 & & & \\
D-dimer & stable & stable & \\
\hline
\end{tabular}

Abbreviations: E2V, estradiol valerate; DNG, dienogest; EE, ethinylestradiol; LNG, levonorgestrel; HDL, high-density lipoprotein; LDL, low-density lipoprotein; SHBG, sex hormon binding globulin.
$30 \mu \mathrm{g}$ EE containing COs than with $50 \mu \mathrm{g}$ EE. ${ }^{47}$ Therefore, development of new oral contraceptive formulation was characterized by a reduction in EE dose to $\leq 20 \mu \mathrm{g}$, which had to be compensated by more potent progestins, in order to maintain the contraceptive efficacy. ${ }^{13}$

In an open-label study, ${ }^{38}$ Qlaira ${ }^{\circledR}$ was compared with Logynon $^{\circledR}$ (triphasic EE/LNG oral contraceptives) in terms of plasma lipids and hemostatic parameters over seven cycles. It was found that levels of prothrombin fragment $1+2$, and D-dimer remained relatively unchanged with E2V/DNG.

In a further open-label crossover study, ${ }^{48}$ women aged 18 to 50 years were randomized to receive the four-phasic oral contraceptive containing E2V/DNG or a monophasic oral contraceptive containing EE $0.03 \mathrm{mg} / \mathrm{LNG} 0.15 \mathrm{mg}$, in order to compare the hemostatic effects. Women received each treatment for three cycles, with two washout cycles between treatments. The primary efficacy variables were the intra-individual absolute changes in prothrombin fragment $1+2$ and D-dimer from baseline to cycle 3 . Secondary efficacy variables included the intra-individual absolute changes in procoagulatory and anticoagulatory parameters from baseline to cycle 3. Data from 29 women were assessed. Overall, changes in hemostatic parameters from baseline to cycle 3 were generally less evident with E2V/DNG than with EE/LNG. ${ }^{48}$ The intra-individual absolute change in prothrombin fragment $1+2$ was $+0.00 \pm 0.04 \mathrm{nmol} / \mathrm{L}$ with $\mathrm{E} 2 \mathrm{~V} / \mathrm{DNG}$, compared with $+0.03 \pm 0.16 \mathrm{nmol} / \mathrm{L}$ with EE/LNG $(P=0.43)$. The intra-individual absolute change in D-dimer with E2V/DNG was $+38.9 \pm 129.9 \mathrm{ng} / \mathrm{mL}$, which was significantly lower $(P=0.01)$ than the change with EE/LNG $(+157.9 \pm 198.3 \mathrm{ng} / \mathrm{mL}){ }^{48}$ The intra-individual absolute change in prothrombin (factor II) was less pronounced with E2V/DNG $(+10.4 \% \pm 17.5 \%)$ vs EE/LNG $(+24.0 \% \pm 13.0 \%) .{ }^{48}$ Changes in procoagulatory parameters were generally less pronounced with E2V/DNG than with $\mathrm{EE} / \mathrm{LNG}{ }^{48}$ The intra-individual absolute change in fibrinogen 
was $+0.3 \pm 1.5 \mathrm{~g} / \mathrm{L}$ with $\mathrm{E} 2 \mathrm{~V} / \mathrm{DNG}$ vs $+0.8 \pm 1.1 \mathrm{~g} / \mathrm{L}$ with EE/LNG. ${ }^{48}$ Corresponding values for factor VII activity were $+2.3 \% \pm 17.2 \%$ and $+6.8 \% \pm 14.2 \%$, respectively. Almost no variation in Factor VIII activity was observed with either E2V/DNG (-1.3\% $\pm 12.9 \%)$ or EE/LNG (+2.6\% $\pm 12.2 \%) .{ }^{48}$ Changes in anticoagulatory parameters were minimal, but tended to be less pronounced with E2V/DNG than with EE/ LNG. ${ }^{48}$ Antithrombin III activity remained stable with E2V/ DNG and EE/LNG, with the intra-individual absolute change being $-0.3 \% \pm 6.5 \%$ and $-3.0 \% \pm 6.7 \%$, respectively. ${ }^{48}$ Changes in protein $\mathrm{C}$ and protein $\mathrm{S}$ activity were minimal with E2V/DNG $(-2.3 \% \pm 14.1 \%$ and $+4.5 \% \pm 11.0 \%$, respectively) and $\mathrm{EE} / \mathrm{LNG}(+5.7 \% \pm 13.6 \%$ and $-0.8 \% \pm$ $20.6 \%$, respectively). ${ }^{48}$ Activated protein C (APC) resistance remained unchanged during the treatment with $\mathrm{E} 2 \mathrm{~V} /$ DNG $(-0.04 \pm 0.28)$ and EE/LNG $(-0.08 \pm 0.40)$. Almost no change was registered in APC sensitivity with E2V/ DNG $(+0.09 \pm 0.43)$, but a slight increase with EE/LNG $(+0.6 \pm 0.7) .{ }^{48}$ Indeed, the innovative four-phasic oral contraceptive composed of E2V/DNG was well-tolerated and had less pronounced effects on hemostatic parameters than a monophasic oral contraceptive composed of EE/LNG. ${ }^{48}$ These findings are consistent with those observed in a study comparing E2V/DNG with a triphasic regimen of EE/LNG, ${ }^{38}$ suggesting that E2V/DNG has a minor impact on hemostatic parameters compared with EE/LNG ${ }^{48}$ (Table 3).

A specific study ${ }^{43}$ was carried out to investigate the effect of an oral contraceptive containing $30 \mu \mathrm{g}$ EE and $2 \mathrm{mg}$ DNG with two different regimens on various hemostatic parameters. Hemostatic parameters were measured in 59 women treated with a monophasic oral contraceptive containing $30 \mu \mathrm{g} \mathrm{EE}+2 \mathrm{mg}$ DNG either conventionally (13 cycles with 21 days of treatment +7 days without hormones) or with an extended-cycle regimen (four extended cycles with 84 days of continuous administration of $\mathrm{EE} / \mathrm{DNG}+7$ days without hormones). ${ }^{43}$ Blood samples were taken on days 21 to 26 of the previous control cycle and on days 19 to 21 of the $3 \mathrm{rd}$ and 13th conventional cycle, or on days 82 to 84 of the first and fourth extended cycle. ${ }^{43}$ After 3 and 12 months, important increases in fibrinogen (20\%), factor VII antigen (50\% to 60\%), factor VII activity (45\%), activated factor VII (30\% to $45 \%)$ and factor VIII activity (10\% to $20 \%$ ) took place in both treatment regimens. In both groups, there was a slight but significant fall in the level and activity of antithrombin, a 20\% to $25 \%$ decrease in total and free protein $\mathrm{S}$ and a $15 \%$ to $20 \%$ increment in the level and activity of protein $\mathrm{C}$, but no relevant variation of the thrombin-antithrombin complex. A significant rise over time of about $25 \%$ of prothrombin fragment $1+2$ occurred only in the
Table 3 Hemostatic parameters change from E2V/DNG compared to $\mathrm{EE} / \mathrm{LNG}$

\begin{tabular}{lll}
\hline & \multicolumn{2}{l}{ Oral contraceptive } \\
\cline { 2 - 3 } & E2V/DNG & EE/LNG \\
\hline Prothrombin & $+0.00 \pm 0.04 \mathrm{nmol} / \mathrm{L}$ & $+0.03 \pm 0.16 \mathrm{nmol} / \mathrm{L}$ \\
fragment I + & & \\
D-dimer & $+38.9 \pm 129.9 \mathrm{ng} / \mathrm{mL}$ & $+157.9 \pm 198.3 \mathrm{ng} / \mathrm{mL}$ \\
Prothrombin & $+10.4 \pm 17.5 \%$ & $+24 \pm 13 \%$ \\
Fibrinogen & $+0.3 \pm 1.5 \mathrm{~g} / \mathrm{L}$ & $+0.8 \pm 1.1 \mathrm{~g} / \mathrm{L}$ \\
FactorVII & $+2.3 \pm 17.2 \%$ & $+6.8 \pm 14.2 \%$ \\
FactorVIII & $-1.3 \pm 12.9 \%$ & $+2.6 \pm 12.2 \%$ \\
Antithrombin III & $-0.3 \pm 6.5 \%$ & $-3.0 \pm 6.7 \%$ \\
Prot C & $-2.3 \pm 14.1 \%$ & $+5.7 \pm 13.6 \%$ \\
Prot S & $+4.5 \pm 11.0 \%$ & $-0.8 \pm 20.6 \%$ \\
APC & $-0.04 \pm 0.28$ & $-0.08 \pm 0.40$ \\
APC sensitivity & $+0.09 \pm 0.43$ & $+0.6 \pm 0.7$ \\
\hline
\end{tabular}

Abbreviations: E2V, estradiol valerate; DNG, dienogest; EE; ethinylestradiol; LNG, levonorgestrel; APC, activated protein C.

extended-cycle group, but this effect did not change significantly from that observed during conventional treatment. Plasminogen increased by $50 \%$ in both groups, while tissue-plasminogen activator (t-PA) activity rose by $15 \%$ in the conventional group and by $25 \%$ to $30 \%$ in the extended-cycle group. In both groups, t-PA antigen was diminished by about $30 \%$ and plasminogen activator inhibitor (PAI)-1 by $40 \%$ to $60 \%$. The levels of the plasmin-antiplasmin complex increased by $30 \%$ to $40 \%$ and those of D-dimers by $20 \%$ to $55 \%$. The prothrombin time was slightly increased and the activated partial thromboplastin time was slightly decreased. ${ }^{43}$

This study clearly demonstrated that there is no significant difference between the conventional and the extended-cycle regimen with respect to any hemostatic parameters at any time, during treatment with EE/DNG.

This is the first double-blind, controlled, randomized study to compare the effect of different estrogen components in oral contraceptives on hemostatic parameters. Four groups of 25 women each were treated for six cycles with monophasic combinations containing 21 tablets with either $30 \mu \mathrm{gEE}+2 \mathrm{mg}$ $\mathrm{DNG}, 20 \mu \mathrm{g} \mathrm{EE}+2 \mathrm{mg} \mathrm{DNG}, 10 \mu \mathrm{g} \mathrm{EE}+2 \mathrm{mg}$ E2 $\mathrm{V}+2 \mathrm{mg}$ $\mathrm{DNG}$, or $20 \mu \mathrm{g} \mathrm{EE}+100 \mu \mathrm{g}$ LNG. Blood samples were taken on days 21 to 26 of the control cycle and on days 18 to 21 of the first, third and sixth treatment cycle. Treatment with all four oral contraceptives provoked an increase in fibrinogen levels, prothrombin fragment $1-2$, D-dimer, plasminogen, and plasmin-antiplasmin complex and protein $\mathrm{C}$ activity, a lower antithrombin activity, t-PA and PAI, and a small decrease in the sensitivity to activated protein $\mathrm{C}$, but no relevant change 
in the thrombin-antithrombin complex. The results, which revealed a rise in protein C activity by $10 \%$ to $15 \%$ of women during use of all four formulations, are in accordance with findings of previous oral contraceptive studies. ${ }^{16,49-58}$ The effects of EE/E2V/DNG on total and free protein $\mathrm{S}$ and on t-PA and PAI were lower compared to $20 \mu \mathrm{g}$ EE $+2 \mathrm{mg}$ DNG effects, suggesting that the impact of $2 \mathrm{mg}$ E2V on several hemostatic parameters is not as much that of $10 \mu \mathrm{g}$ EE. The fall of total and free protein S observed in the present study with the DNG-containing oral contraceptives was also in the range of the results of previous studies. ${ }^{49-61}$

The results show an antagonistic effect of LNG on the EE-induced rise of factor VII activity and fragment $1+2$ and on the EE-dependent reduction of total and free protein S. ${ }^{13}$

In the previous study, no significant differences between the four formulations were observed in their effect on most hemostatic parameters, except those on total and free protein $\mathrm{S}$, and on factor VII in cycle 6 . In fact, total and free protein S decreased according to the $\mathrm{EE}$ dose during treatment with oral contraceptives containing DNG, and the effect of EE/E2V/DNG was less compared to that of $20 \mathrm{EE} / \mathrm{DNG}$. The results suggest that $10 \mu \mathrm{g}$ EE combined with DNG exerts a stronger effect on some hemostatic parameters than $2 \mathrm{mg}$ E2 $\mathrm{V}^{13}$

\section{Safety}

\section{Adverse events and tolerability}

A randomized comparative trial $^{7}$ reported adverse reactions in $10.0 \%$ and $8.5 \%$ of women receiving $\mathrm{E} 2 \mathrm{~V} / \mathrm{DNG}$ and $\mathrm{EE} / \mathrm{LNG}$, respectively. The most common adverse events were breast pain, headache, acne, alopecia, migraine and an increase of bodyweight. ${ }^{7}$ The most frequent adverse events in women treated with E2V/DNG were breast pain (3.8\%), headache $(2.5 \%)$, and vaginal infection $(2.5 \%)$, while the most frequently reported adverse events in women treated with EE/ LNG were acne $(3.3 \%)$, headache $(3.3 \%)$, and nasopharyngitis $(1.8 \%)$. The incidence of dysmenorrhea in the preceding 6 months was $9.5 \%$ in the E2V/DNG group, and $6.8 \%$ in the $\mathrm{EE} / \mathrm{LNG}$ group, but during the study, the reported incidence of dysmenorrhea was $0.5 \%$ in both treatment groups. ${ }^{7}$

The frequency (10.0\% vs $8.5 \%$ ) and nature of treatmentrelated adverse events was generally similar between the E2V/DNG and EE/LNG treatment groups. ${ }^{7}$ Serious adverse events occurred in four E2V/DNG recipients and three EE/LNG recipients. None of the serious adverse events reported were deemed to be related to the study medication, apart from a ruptured ovarian cyst, autonomic nervous system imbalance (one E2V/DNG recipient) and breast cancer (one EE/LNG recipient). ${ }^{7}$ No deaths were reported. ${ }^{7}$
Endrikat et $\mathrm{al}^{22}$ reported only one serious adverse event in a woman in study 1 (regimen 1A) considered possibly treatment related (ovarian cyst). No deaths occurred during the studies. ${ }^{22}$ In study I, four women had adverse events considered possibly related to treatment that resulted in study discontinuation (regimen $1 \mathrm{~A}, \mathrm{n}=2$ [ovarian cyst, breast pain]; regimen $2 \mathrm{~A}, \mathrm{n}=2$ [edema, diarrhea]). ${ }^{22}$ Eight women in study 2 , had treatment-related adverse events that resulted in discontinuation of treatment (regimen $2 \mathrm{~B}, \mathrm{n}=5$ [depression, headache, worsening acne, eye irritation, furunculousis]; regimen $2 \mathrm{C}, \mathrm{n}=3$ [emotional liability, $\mathrm{n}=2$, headache]). ${ }^{22}$

In the non-comparative study, treatment-related adverse events occurred in 272 women $(19.8 \%){ }^{29}$

The most frequently reported treatment-emergent adverse events in women aged 18 to 50 years in the pooled analysis $(n=2266)$ were breast discomfort $(4.9 \%$ of women), metrorrhagia (4.9\%) and headache $(3.1 \%){ }^{62}$ Other treatment-emergent adverse events occurring in $\geq 1 \%$ of women included acne $(2.8 \%$ of women $)$, increase in bodyweight $(1.5 \%)$, amenorrhea $(1.7 \%)$, dysmenorrhea $(1.7 \%)$ and abdominal pain $(1.7 \%){ }^{62}$

In the study by Parke et $\mathrm{al}^{48}$ the proportion of women reporting adverse events was generally similar in both treatment groups. No adverse events were rated as serious. ${ }^{48}$

\section{Satisfaction}

In the open-label 20-cycle study ( $\mathrm{n}=1377), 79,5 \%$ of women were either satisfied or very satisfied with Qlaira ${ }^{\circledR}$, and just over two-thirds of the full analysis set would consider taking Qlaira $^{\circledR}$ in the future. Only $7.4 \%$ were dissatisfied or very dissatisfied. One hundred and forty-two women complained because of adverse events but only 37 discontinued use because of irregular menstrual bleeding. ${ }^{29}$

In the study by Ahrendt et al, ${ }^{7} 79.4 \%$ of women were satisfied with E2V/DNG and 79.9\% with EE/LNG; 39.8\% of women were very satisfied with E2V/DNG and $35.3 \%$ of women were very satisfied with EE/LNG.

\section{Contraindications}

$\mathrm{E} 2 \mathrm{~V} / \mathrm{DNG}$ is contraindicated only in women with an acquired or hereditary predisposition for arterial or venous thrombosis; a history of or current episodes of arterial thrombosis, cerebrovascular accident, liver cancer, pancreatitis (if associated with severe hypertriglyceridemia), severe hepatic disease or venous thrombosis; a history of migraine with focal neurological symptoms; hypersensitivity to the active substances or to any of the excipients; known or suspected sex-steroid influenced cancer; the presence of 
severe or multiple arterial or venous thrombosis risk factors, including diabetes mellitus with vascular symptoms, severe dyslipoproteinemia and severe hypertension or undiagnosed vaginal bleeding. ${ }^{3}$

\section{Discussion}

The dose of EE has been progressively reduced over time, and contraceptives containing $20 \mu \mathrm{g}$ or even $15 \mu \mathrm{g}$ of EE are currently available. However, EE dose will be unlikely to be further reduced, due to the possible occurrence of symptoms of low estrogen levels. ${ }^{63}$ Furthermore, some studies have suggested that a daily dose of $10 \mu \mathrm{g}$ may have unfavorable impact on hemostatic parameters. ${ }^{14}$ The objective was to develop hormonal contraceptives containing natural estrogens like E2, which is structurally identical to endogenous estradiol.

DNG was included as the progestin component, as it is known to have a relevant protective function on the endometrium, ${ }^{64}$ it is well tolerated and associated with excellent contraceptive efficacy when combined with EE. ${ }^{65-68}$ However, previous attempts to replace EE with E2 proved to be somewhat unsatisfactory with respect to cycle control, ${ }^{26-28}$ particularly when E2 was administered as part of a monophasic or a biphasic regimen. Therefore, previous studies, which were carried out in an iterative stepwise manner, have shown that the current regimen (E2V $3 \mathrm{mg}$ for 2 days, followed by E2V/DNG $2 \mathrm{mg} / 2 \mathrm{mg}$ for 5 days, E2V/DNG $2 \mathrm{mg} / 3 \mathrm{mg}$ for 17 days, E2V $1 \mathrm{mg}$ for 2 days and placebo for 2 days) contains the optimal dose of $\mathrm{DNG}$ necessary for efficient ovulation inhibition when combined with $\mathrm{E} 2 \mathrm{~V}^{7}$ The dynamic dosing regimen was designed to ensure estrogen dominance in the first part of the cycle and progestin dominance in the middle to the later part of the cycle, thereby optimizing the bleeding pattern. Early estrogenic dominance is hypothesized to ensure initial endometrial proliferation and severity for mid-cyclic progestin action and endometrial stroma stability, particularly towards the end of the cycle. ${ }^{7}$

Women who received E2V/DNG have fewer bleeding/ spotting days and fewer bleeding/spotting episodes than women who received $\mathrm{EE} / \mathrm{LNG}$; accordingly, an absence of withdrawal bleeding in cycles 1 to 7 occurred more often in women treated with E2V/DNG than with EE/LNG. Over seven cycles of treatment, the mean length of withdrawal bleeding was slightly shorter in women treated with E2V/ DNG compared with women treated with EE/LNG; and the maximum intensity of withdrawal bleeding was more often spotting and light bleeding in women treated with E2V/DNG.
Conversely, the maximum intensity of withdrawal bleeding was more often normal or heavy in women treated with EE/LNG. ${ }^{7}$ The oral contraceptive composed of E2V/DNG is comparable to EE-containing oral contraceptive in terms of bleeding profile. ${ }^{7}$ Indeed, E2V/DNG showed an acceptable bleeding pattern and level of cycle control.

This novel oral contraceptive containing E2V and DNG is effective and well-tolerated, ${ }^{31}$ delivers stable levels of E2 throughout the cycle ${ }^{65}$ and is associated with a reduced impact on hemostatic and metabolic parameters compared with EE/LNG. ${ }^{7,38}$

In users of the DNG-containing oral contraceptives, the reduction in total and free protein $\mathrm{S}$, and in t-PA and PAI was dependent on the EE dose, while factor VII activity was elevated, but not significantly different from that with EE/LNG. ${ }^{13}$ The levels of high-density lipoprotein cholesterol increased, while the levels of prothrombin fragment $1+2$ and D-dimer remained relatively unchanged; in contrast, the levels of SHBG, CBG and TBG increased. ${ }^{38}$

The finding that Qlaira ${ }^{\circledR}$ has a reduced metabolic impact when compared to EE/LNG-containing oral contraceptives, may attract particularly women aged over 35 years old or women with uncomplicated diabetes. Qlaira ${ }^{\circledR}$ may be very suitable also for women complaining of "estrogen withdrawal symptoms" such as headache or mood changes, because about $20 \%$ of women each month have no withdrawal bleed using Qlaira ${ }^{\circledR} \cdot{ }^{25}$

The Qlaira ${ }^{\circledR}$ regimen provides reliable contraceptive efficacy $^{7,29}$ and has been shown to be well tolerated, ${ }^{29}$ with stable serum E2 levels maintained throughout the cycle. ${ }^{65}$

In fact, about $79.4 \%$ of women were satisfied with E2V/DNG. ${ }^{7,29}$

We have no data on the efficacy and tolerability of E2V/DNG in adolescents aged $<18$ years. ${ }^{3}$

\section{Conclusion}

The previous attempts to use natural estrogens, such as E2, for hormonal contraception were unsatisfactory in terms of cycle control because of the use of suboptimal doses of E2 and of the inappropriate ratio of estrogen to progestin. The natural E2 and the progestin DNG have been combined in a unique dynamic dosing regimen with four hormonal dosage steps in which estrogen and progestin doses follow as closely as possible the menstrual cycle physiology. E2V/DNG is the best combination to guarantee a good control of the menstrual cycle, together with high contraceptive safety, high tolerability and a reduced metabolic impact. 


\section{Disclosure}

The authors declare no conflicts of interest.

\section{References}

1. Mosher WD, Martinez GM, Chandra A, Abma JC, Willson SJ. Use of contraception and use of family planning services in the United States: 1982-2002. Adv Data. 2004;350:1-36.

2. Meade TW. Risks and mechanisms of cardiovascular events in users of oral contraceptives. Am J Obstet Gynecol. 1988;158:1646-1652.

3. Emc.Medicine.org [homepage on the Internet]. Qlaira ${ }^{\circledR}$ - Summary of product Characteristics (SPC). Bayer Schering Pharma. http://emc.medicines.org.uk/medicine/21700/SPC/Qlaira ${ }^{\circledR} /$. Accessed November 17, 2009.

4. Loose DS, Stancel GM. Estrogens and progestins. In: Brunton LL, Lazo JS, Parker KL, editors. Goodman and Gilman's the Pharmacological Basis of Therapeutics. 11th ed. New York: McGraw-Hill; 2005. p. $1541-1571$.

5. Graziottin A. Che cosa vogliono le donne nella contraccezione. Che cosa può offrire Klaira. Contraccezione Fertilità Sessualità. Numero speciale. 2009;36:23-28.

6. Nappi RE. Profilo farmacologico di Qlaira ${ }^{\circledR}$. Contraccezione Fertilità Sessualità. Numero speciale. 2009;36:5-10.

7. Ahrendt HJ, Makalová D, Parke S, Mellinger U, Mansour D. Bleeding pattern and cycle control with an estradiol-based oral contraceptive: a seven-cycle, randomized comparative trial of estradiol valerate/ dienogest and ethinyl estradiol/levonorgestrel. Contraception. 2009;80(5):436-444.

8. Zeun S, Lu M, Uddin A, Zeiler B, Morrison D, Blode H. Pharmacokinetics of an oral contraceptive containing oestradiol valerate and dienogest. Eur J Contracept Reprod Health Care. 2009;14(3):221-232.

9. Oettel M, Graser T, Hoffman H. Why dienogest as a progestogenic component of postmenopausal nonandrogenic hormone replacement therapy. Drugs Today (Barc). 2001;37:3-15.

10. Mueck AO, Seeger H. Pharmacology of dienogest. Gyneacology Forum. 2009;14:9-12.

11. Zimmerman H, Thebault JJ, Duvauchelle T, et al. Pharmacokinetics of estradiol valerate $2 \mathrm{mg}$ + dienogest $2 \mathrm{mg}$ after single and repeated oral administration in healty postmenopausal women. Clin Drug Investig. 2000;20:123-134.

12. Mashchak CA, Lobo RA, Dozono-Takano R, et al. Comparison of pharmacodynamic properties of various estrogen formulations. Am J Obstet Gynecol. 1982;144(5):511-518.

13. Wiegratz I, Lee JH, Kutschera E, Winkler UH, Kuhl H. Effect of four oral contraceptives on hemostatic parameters. Contraception. 2004;70(2):97-106.

14. Lindberg UB, Crona N, Stigendal L, Teger-Nilsson AC, Silfverstolpe G. A comparison between effects of estradiol valerate and low dose ethinynil estradiol on haemostasis parameters. Thromb Haemost. 1989;61(1):65-69.

15. Helgason S. Estrogen replacement therapy after the menopause. Estrogenicity and metabolic effects. Acta Obstet Gynecol Scand Suppl. 1982;107:1-29.

16. Oral Contraceptive and Hemostasis Study Group. The effects of seven monophasic oral contraceptive regimens on hemostatic variables: conclusions from a large randomized multicenter study. Contraception. 2003;67(3):173-185.

17. Kuhl H. Effects of progestogens on haemostasis. Maturitas. 1996;24(1-2):1-19.

18. Winkler UH. Effects on hemostatic variables of desogestrel- and gestodene-containing oral contraceptives in comparison with levonorgestrel-containing oral contraceptives: a review. Am J Obstet Gynecol. 1998;179(3 Pt 2):S51-S61.

19. Norris LA, Bonnar J. The effect of oestrogen dose and progestogen type on haemostatic changes in women taking low dose oral contraceptives. Br J Obstet Gynaecol. 1996;103(3):261-267.
20. Mueck AO, Seeger H, Lüdtke R, Gräser T, Wallwiener D. Effect on biochemical vasoactive markers during postmenopausal hormone replacement therapy: estradiol versus estradiol/dienogest. Maturitas. 2001;38(3):305-313.

21. Blode H, Schott B, Rohde M, Kunz M, Zeun S, editors. Effects of CY3A4 induction and inhibition on the pharmacokinetics of estradiol valerate/dienogest. Proceedings of the 11th world congress on controversies in obstetrics gynecology and infertility; 2008 Nov. p. 27-30; Paris, France.

22. Endrikat J, Parke S, Trummer D, Schmidt W, Duijkers I, Klipping C. Ovulation inhibition with four variations of a four-phasic estradiol valerate/dienogest combined oral contraceptive: results of two prospective, randomized, open-label studies. Contraception. 2008;78(3):218-225.

23. Moore C, Feichtinger W, Klinger G, et al. Clinical findings with the dienogest-containing oral contraceptive Valette ${ }^{\circledR}$. Drugs Today (Barc). 1999;35 Suppl C:53-68.

24. Hoogland HJ, Skouby SO. Ultrasound evaluation of ovarian activity under oral contraceptives. Contraception. 1993;47(6):583-590.

25. Mansour D. Qlaira ${ }^{\circledR}:$ a natural change of direction. J Fam Plann Reprod Health Care. 2009;35(3):139-142.

26. A randomized, double-blind study of two combined oral contraceptives containing the same progestogen, but different estrogens. World Health Organization Task Force on Oral Contraception. Contraception. 1980;21(5):445-459.

27. Schubert W, Cullberg G. Ovulation inhibition with 17 beta-estradiol cyclo-octyl acetate and desogestrel. Acta Obstet Gynecol Scand. 1987;66(6):543-547.

28. Serup J, Bostofte E, Larsen S, Westergaard J, Lebech PE. Natural oestrogens for oral contraception. Lancet. 1979;2(8140): 471-472.

29. Nahum GG, Parke S, Wildt L, et al. Efficacy and tolerability of a new oral contraceptive containing estradiol and dienogest [abstract]. Obstet Gynecol. 2008;111 Suppl 4:S15. Poster presentation from the American College of Obstetricians and Gynecologists 56th Annual Clinical Meeting; 2008 May 3-7; New Orleans, LA.

30. Wiegratz I, Kutschera E, Lee JH, et al. Effect of four different oral contraceptives on various sex hormones and serum-binding globulins. Contraception. 2003;67(1):25-32.

31. Refn H, Kjaer A, Lebech AM, Borggaard B, Schierup L. Clinical and hormonal effects of two contraceptives: correlation to serum concentrations of levonorgestrel and gestodene. Contraception. 1990;41(3): 259-269.

32. Kuhl H, Jung-Hoffmann C, Weber J, Boehm BO. The effect of a biphasic desogestrel-containing oral contraceptive on carbohydrate metabolism and various hormonal parameters. Contraception. 1993;47(1): $55-68$.

33. Gaspard UJ, Romus MA, Gillain D, Duvivier J, Demey-Ponsart E, Franchimont P. Plasma hormone levels in women receiving new oral contraceptives containing ethinyl estradiol plus levonorgestrel or desogestrel. Contraception. 1983;27(6):577-590.

34. Aden U, Jung-Hoffmann C, Kuhl H. A randomized cross-over study on various hormonal parameters of two triphasic oral contraceptives. Contraception. 1998;58(2):75-81.

35. Kuhl H, Gahn G, Romberg G, März W, Taubert HD. A randomized cross-over comparison of two low-dose oral contraceptives upon hormonal and metabolic parameters: I. Effects upon sexual hormone levels. Contraception. 1985;31(6): 583-593.

36. Jung-Hoffmann C, Heidt F, Kuhl H. Effect of two oral contraceptives containing 30 micrograms ethinylestradiol and 75 micrograms gestodene or 150 micrograms desogestrel upon various hormonal parameters. Contraception. 1988;38(6): 593-603.

37. Luciano AA, Sherman BM, Chapler FK, Hauser KS, Wallace RB. Hyperprolactinemia and contraception: a prospective study. Obstet Gynecol. 1985;65(4):506-510. 
38. Parke S, Nahum GG, Mellinger U, Junge W. Metabolic effects of a new 4-phasic combined oral contraceptive containing estradiol valerate and dienogest. Poster presented at the American College of Obstericians and Gynecologists 56th Annual Meeting; 2008 May 3-7; New Orleans, LA. Obstet and Gynecol. 2008;111 Suppl 4:125.

39. Helmerhorst FM, Rosendaal FR, Vandenbroucke JP. Venous thromboembolism and the pill. The WHO technical report on cardiovascular disease and steroid hormone contraception: stateof-the-art. World Health Organization. Hum Reprod. 1998;13(11): 2981-2983.

40. Herings RM, Urquhart J, Leufkens HG. Venous thromboembolism among new users of different oral contraceptives. Lancet. 1999;354(9173):127-128.

41. Bloemenkamp KW, Rosendaal FR, Helmerhorst FM, Vandenbroucke JP. Higher risk of venous thrombosis during early use of oral contraceptives in women with inherited clotting defects. Arch Intern Med. 2000;160(1):49-52.

42. Lidegaard O, Edström B, Kreiner S. Oral contraceptives and venous thromboembolism: a five-year national case-control study. Contraception. 2002;65(3):187-196.

43. Wiegratz I, Stahlberg S, Manthey T, et al. Effects of conventional or extended-cycle regimen of an oral contraceptive containing $30 \mathrm{mcg}$ ethinylestradiol and $2 \mathrm{mg}$ dienogest on various hemostasis parameters. Contraception. 2008;78(5):384-391.

44. Meade TW. Oral contraceptives, clotting factors, and thrombosis. Am J Obstet Gynecol. 1982;142(6 Pt 2):758-761.

45. Gerstman BB, Piper JM, Tomita DK, Ferguson WJ, Stadel BV, Lundin FE. Oral contraceptive estrogen dose and the risk of deep venous thromboembolic disease. Am J Epidemiol. 1991;133(1):32-37.

46. Lidegaard $\mathrm{O}$. Oral contraception and risk of a cerebral thromboembolic attack: results of a case-control study. BMJ. 1993;306(6883):956-963.

47. Sabra A, Bonnar J. Hemostatic system changes induced by 50 micrograms and $30 \mathrm{micrograms}$ estrogen/progestogen oral contraceptives. Modification of estogen effects by levonorgestrel. J Reprod Med. 1983;28 Suppl 1:S85-S91.

48. Parke S, Junge W, Mellinger U, Duijkers I, Klipping C. Comparative effects of four-phasic regimen of estradiol valerate/dienogest versus ethinylestradiol/levonorgestrel on haemostatic parameters. Proceeding of the 24th Annual Meeting of the ESHRE; 2008 July 7-9; Barcelona, Spain.

49. Spona J, Feichtinger W, Kindermann C, et al. Double-blind, randomized, placebo controlled study on the effects of the monophasic oral contraceptive containing 30 micrograms ethinyl estradiol and $2.00 \mathrm{mg}$ dienogest on the hemostatic system. Contraception. 1997;56(2):67-75.

50. Winkler UH, Schindler AE, Endrikat J, Düsterberg B. A comparative study of the effects of the hemostatic system of two monophasic gestodene oral contraceptives containing 20 micrograms and 30 micrograms ethinylestradiol. Contraception. 1996;53(2):75-84.

51. Winkler UH, Daume E, Sudik R, et al. A comparative study of the hemostatic effects of two monophasic oral contraceptives containing $30 \mu \mathrm{g}$ ethinylestradiol and either $2 \mathrm{mg}$ chlormadinone acetate or $150 \mu \mathrm{g}$ desogestrel. Eur J Contracept Reprod Health Care. 1999;4(3):145-154.

52. Quehenberger P, Loner U, Kapiotis S, et al. Increased levels of activated factor VII and decreased plasma protein S activity and circulating thrombomodulin during use of oral contraceptives. Thromb Haemost. 1996;76(5):729-734.
53. Winkler UH, Hölscher T, Schulte H, Zierleyn JP, Collet W, Schindler AE. Ethinylestradiol 20 versus 30 micrograms combined with 150 micrograms desogestrel: a large comparative study of the effects of two lowdose oral contraceptives on the hemostatic system. Gynecol Endocrinol. 1996;10(4):265-271.

54. Winkler UH, Oberhoff C, Bier U, Schindler AE, Gillain D. Hemostatic effects of two oral contraceptives containing low doses of ethinyl estradiol and either gestodene or norgestimate: an open, randomized, parallel-group study. Int J Fertil Menopausal Stud. 1995;40(5):260-268.

55. Cachrimanidou AC, Hellberg D, Nilsson S, von Schoulz B, Crona N, Siegbahn A. Hemostasis profile and lipid metabolism with long-interval use of a desogestrel-containing oral contraceptive. Contraception. 1994;50(2):153-165.

56. Tans G, Curvers J, Middeldorp S, et al. A randomized cross-over study on the effects of levonorgestrel- and desogestrel-containing oral contraceptives on the anticoagulant pathways. Thromb Haemost. 2000;84(1):15-21.

57. Malm J, Laurell M, Dahlbäck B. Changes in the plasma levels of vitamin Kdependent proteins $\mathrm{C}$ and $\mathrm{S}$ and of $\mathrm{C} 4 \mathrm{~b}$-binding protein during pregnancy and oral contraception. Br J Haematol. 1988;68(4):437-443.

58. Petersen KR, Sidelmann J, Skouby SO, Jespersen J. Effects of monophasic low-dose oral contraceptives on fibrin formation and resolution in young women. Am J Obstet Gynecol. 1993;168(1 Pt 1):32-38.

59. Archer DF, Mammen EF, Grubb GS. The effects of a low-dose monophasic preparation of levonorgestrel and ethinyl estradiol on coagulation and other hemostatic factors. Am J Obstet Gynecol. 1999;181(5 Pt 2):63-66.

60. Melissari E, Kakkar VV. The effects of oestrogen administration on the plasma free protein $\mathrm{S}$ and $\mathrm{C} 4 \mathrm{~b}$-binding protein. Thromb Res. 1988;49(5):489-495.

61. Granata A, Sobbrio GA, D'Arrigo F, et al. Changes in the plasma levels of proteins $\mathrm{C}$ and $\mathrm{S}$ in young women on low-dose oestrogen oral contraceptives. Clin Exp Obstet Gynecol. 1991;18(1):9-12.

62. Nelson A, Sampson-Landers C, Parke S, et al. Efficacy of estradiol valerate/dienogest oral contraceptive: results of 3 large studies in North America and Europe [abstract plus poster]. Proceeding of the American College of Obstetricians and Gynecologists 57th Annual Clinical Meeting; 2009 May 2-6; Chicago, IL.

63. Fruzzetti F, Perini D, Lazzarini V. Etinil Estradiolo diventa Estradiolo. Profilo clinico di Klaira. Contraccezione Fertilità Sessualità. Numero speciale. 2009;36:11-18.

64. Oettel M, Carol W, Elger W, et al. A 19-norprogestin without 17alfa-ethinil group II: dienogest from a pharmacodynamic point of view. Drugs Today (Barc). 1995;31:517-536.

65. Lu M, Uddin A, Foegh M, Zeun S. Pharmacocynetics and pharmacodynamic of a new four-phasic estradiol valerate and dienogest oral contraceptive. Obstet Gynecol. 2007;109:61S.

66. Golbs S, Domhardt R, Presl J, et al. Clinical findings with the oral contraceptive combination ethinylestradiol/dienogest in the Czech Republic. Methods Find Exp Clin Pharmacol. 2002;24:689-696.

67. Golbs S, Domhardt R, Radowicky S, et al. Clinical findings with the oral contraceptive combination ethinylestradiol/dienogest in Poland. Methods Find Exp Clin Pharmacol. 2002;24:585-592.

68. Zimmermann T, Dietrich H, Wisser KH, Hoffmann H. The efficacy and tolerability of Valette: a post marketing surveillance study. Eur J Contracept Reprod Health Care. 1994;4:155-164.
International Journal of Women's Health

\section{Publish your work in this journal}

The International Journal of Women's Health is an international, peerreviewed open-access journal publishing original research, reports, reviews and commentaries on all aspects of women's healthcare including gynecology, obstetrics, and breast cancer. Subject areas include: Chronic conditions (migraine headaches, arthritis, osteoporosis);

\section{Dovepress}

Endocrine and autoimmune syndromes; Sexual and reproductive health; Psychological and psychosocial conditions. The manuscript management system is completely online and includes a very quick and fair peer-review system. Visit http://www.dovepress.com/ testimonials.php to read real quotes from published authors. 